\title{
TRADIÇÃO E MODERNIDADE: RECONFIGURAÇÕES IDENTITÁRIAS NA MÚSICA FOLCLÓRICA CHILENA DOS ANOS 1950 E 1960
}

Tânia da Costa Garcia*

garcosta@uol.com.br

\begin{abstract}
RESUMO: A canção popular urbana constitui uma manifestação cultural tipicamente moderna. Sua produção, circulação e consumo se confundem com o processo de urbanização e com a disponibilidade de recursos tecnológicos. Veiculada pelos meios de comunicação de massa, ao alcançar públicos bem mais amplos que os receptores locais, não demorou para se traduzir num importante vetor de homogeneização cultural, afeita à lógica de mercado. Neste artigo, objetiva-se mapear as conexões entre a canção popular, a formação e a consolidação de um mercado consumidor, bem como os usos políticos do gênero por diferentes setores da sociedade chilena entre os anos 50 e 60 , período em que as artes estiveram relacionadas às lutas das representações em torno da identidade nacional em diferentes países da América Latina.
\end{abstract}

Palavras-chave: Música folclórica, identidade nacional e cultural jovem.

A idéia de nação, tão imbricada à modernidade, parece muitas vezes preceder a própria história. A história da nação, nos países do continente americano, é narrada desde sua "origem", qual seja, o "descobrimento", passando pelo processo de colonização até a conquista da independência como um devir conhecido. A história da nação transforma-se, assim, na história contra seus opressores.

Entretanto, é somente a partir desta autonomia política, conquistada através de acordos e/ou rupturas que se coloca a necessidade de dar sentido a tal unidade. Desde então, são identificados laços comuns entre aqueles que habitam o mesmo território. Tal construção integra o imaginário, lugar habitado pelas paixões e desejos humanos, que, por sua vez, compõem o real. Através de laços identitários pré-existentes e/ou inventados (imaginados) - conjunto de valores, símbolos, lembranças e mitos disponíveis - constitui-se a identidade nacional (SмITH, 1998).

Professora do Departamento de História da UNESP/Franca. 
Tais prefigurações fundadoras de um nacional, fundamentadas no social e no político, foram e são constantemente reinterpretadas pelas sucessivas gerações. Em cada época, utiliza-se dos suportes disponíveis para a produção, difusão e fixação de um universo simbólico comum. Diferentemente do século XIX em que predominou o uso da imprensa escrita e, portanto, da cultura letrada, no século XX, para a produção e reprodução das identidades nacionais, fez-se largo uso do rádio, do fonograma, do cinema e da televisão, a fim de promover um conjunto de imagens e símbolos capazes de integrar a nação. $\mathrm{Na}$ América Latina, o papel de tais veículos foi demasiadamente importante, uma vez que a escrita, mesmo quando iniciado o século, era ainda de domínio restrito. Como bem observa MartinBarbero (1997), distintamente da trajetória européia, praticamente saltamos da cultura oral para a midiática, sem assentarmos lastro na cultura escrita, que, entre nós, se desenvolveu, paralela e concorrencialmente, àquela propagada pelos meios de comunicação de massa.

Assim, exercer algum tipo de influência e controle sobre os meios de comunicação e seus conteúdos, passou a ser de fundamental importância para o Estado-nação, frente às novas demandas sociais. No subcontinente, o desenvolvimento destes suportes na sua primeira fase coincidiu com a intensificação da migração do campo para a cidade entre os anos 1920 e 1930, com a chegada de levas de imigrantes em decorrência das crises econômicas da Europa do pós-guerra e com o inicio da industrialização, resultando numa configuração social mais complexa do espaço urbano, o que exigiu uma nova organização política, sustentada em novos laços de solidariedade. Carecia-se de uma reconfiguração do simbólico nacional capaz de integrar estes novos atores sociais à nação. Nesse processo de construção e reconstrução identitárias, diferentes apropriações do universo denominado popular estiveram em pauta. ${ }^{1}$

Este movimento de elaboração e re-elaboração das representações do nacional, vivenciado nas primeiras décadas do século XX, foi, após a Segunda Grande Guerra, retomado em novas bases, em diferentes países da América Latina. A vitória dos aliados no conflito mundial, ao projetar os Estados Unidos como nação hegemônica na política internacional, aumentou sua influência sobre os países abaixo do Rio Grande. Ao mesmo tempo, as transformações sociais, econômicas e culturais decorrentes dos avanços tecnológicos, de um mercado mais dinâmico, internamente alimentado pelo crescimento demográfico das cidades e externamente pela intensificação das trocas em nível mundial, materializaram-se na presença de um outro, sob a forma de uma cultura distinta, propagada pelos meios 
de comunicação de massa (rádio, cinema e indústria fonográfica). Tal fato provocaria nas sociedades latino-americanas um desenraizamento do tempo presente, um retorno ao passado. Em busca de uma identidade perdida supervalorizou-se, desde então, a tradição, o genuinamente nacional.

Neste cenário, os estudos folclóricos ganharam um novo fôlego. No Chile, particularmente a música folclórica recebeu a atenção de diferentes setores da sociedade, desde os intelectuais ligados a Universidade, cujas pesquisas envolviam o folclore e a música douta, passando pelos governos radicais que atuaram através de organismos específicos controlando, fiscalizando e incentivando a produção e difusão da música popular chilena, até a indústria fonográfica e as emissoras comerciais de rádio. Assim sendo, esta atenção advinha do universo do entretenimento, que, envolvido nesta atmosfera nacionalista, passou a investir nos gêneros e a integrar as polêmicas em torno do tema. Neste artigo, serão enfocados exclusivamente os aspectos relacionados à indústria do entretenimento.

Nessa operação de folclorização, o popular foi transformado em tradição (CANCLINI, 1998). Para se tradicionalizar o popular foi necessário primeiro atribuí-lo ao passado - lugar onde supostamente era encontrado em estado puro - e, em seguida, fixá-lo, museificá-lo a partir de critérios ideologicamente constituídos no presente. A seleção desse repertório implicou num processo de inclusão e exclusão. Isto é, "os elementos que compunham a tradição, sua invariabilidade, repetição e permanência" (HOBSBAWM; RANGER, 1997) foram eleitos tendo como referência o seu contrário, o diverso, a descontinuidade, a ameaça de mudança.

Se, por um lado, este discurso pode hoje ser facilmente taxado de conservador, quando não de reacionário, por outro, faz-se necessário entendê-lo historicamente. Foram os folcloristas um dos primeiros a se preocuparem com o sentimento de identidade, com a definição de um "caráter nacional", pautados em conceitos e argumentos científicos.

Concordo com Luis Rodolfo Vilhena (1997, p. 29), que propõe, antes de condenar e descartar os estudos folclóricos, a seguinte indagação:

por que foi e em que medida o foi, importante para segmentos significativos de intelectuais, em diferentes contextos nacionais e institucionais, focalizar a cultura popular, mesmo que vista por um sem número de vieses deformantes, e tomá-la como fonte de respostas para os seus anseios de compreender e definir o caráter nacional?

Retomo esta questão lançada pelo referido autor, a fim de analisar as formas pelas quais se deu, no Chile, nas décadas de 1950 e 1960 - período

Tânia da Costa Garcia. Tradição e Modernidade: reconfigurações identitárias... 
de intensas transformações sociais, políticas e culturais -, esta retomada do popular, em particular da música folclórica, enfocando as configurações e reconfigurações deste repertório atrelado às representações do nacional.

\section{A MÚSICA TÍPICA CHILENA OU O FOLCLORE MASSIVO}

A revalorização da música folclórica e sua expansão no meio urbano estiveram associadas à inversão da lógica de ocupação do espaço. Dos anos 1950 para os anos 1960, com o crescimento da industrialização e o incremento das trocas comerciais, a população das cidades tornava-se superior a do campo, surgindo, de forma incipiente e setorizada ${ }^{2}$, uma sociedade de consumo em diferentes países da América Latina, dentre eles o Chile.

A nova demanda de consumo e a atmosfera nacionalista do período foram responsáveis por um aquecimento do mercado discográfico que, além dos ritmos estrangeiros, passava a incluir, com maior intensidade, um casting de músicos nacionais. As emissoras de rádio, por sua vez, responderam a esta tendência com um espaço maior na programação dedicado ao gênero. Nos anos 1950, ofereciam aos ouvintes uma música folclórica estilizadas. Grupos e duos como Los Hermanos Lagos, Los Provincianos, Los Cuatro Hermanos Silva, Margarita Alarcon, Silvia Infantas e Los Baqueanos, Duo Rey-Silva, Esther Soré promoviam um repertório conhecido como "música típica chilena". Música que resultava de uma adaptação do cancioneiro tradicional de origem rural às tecnologias dos suportes, ao show business e à escuta de uma população que se urbanizava sem, todavia, abandonar totalmente as referências de uma cultura campesina. Tal repertório era, portanto, comprometido com o perfil deste público de transição, a despeito de seus compositores e intérpretes reivindicarem seu pertencimento à tradição.

As inovações ou "desvios", esses últimos na concepção dos mais puristas, iam desde as harmonizações, o uso excessivo de instrumentos, o canto coral até o vestuário inspirado nos huasos domingueiros.

Numa entrevista concedida à revista Radiomania, indagada sobre a qualidade destes grupos de música típica, Violeta Parra (1954, p. 18), afirmava:

A única intérprete verdadeira é Margot Loyola. Que pena me dá ver tantos elementos de qualidade como o Duo Rey Silva, o Duo Bascuña Del Campo, Margarita Alarcon e tantos outros que não tem uma orientação clara a respeito de como se interpreta o folclore. Gostaria de formar um curso de orientação histórica da canção chilena, onde os intérpretes pu- 
dessem aprender o verdadeiro folclore, a maneira de interpretá-lo, suas raízes. Faria isto com toda alma, sem cobrar nada. É um crime o que intérpretes de qualidade estão cantando e gravando, mambo, baião, etc. $[\ldots]$.

Terminado os anos 1950, o trabalho destes grupos, que estiveram em cartaz desde finais da década de 1940, sofreria um desgaste natural, como a grande maioria dos gêneros massivos. Em Ecran, datam do final desta época as primeiras matérias reclamando da falta de espaço para a música folclórica nas rádios chilenas. O período teve forte concorrência do bolero - que desde meados dos anos 40 estava entre as preferidas dos ouvintes -, da balada e do rock norte-americano que começavam a ter suas versões com intérpretes nacionais.

Com a renovação dos artistas e do público, representados, sobretudo, pela juventude, tinha início uma mudança radical nos meios de comunicação de massa. Desde então, surgiram no Chile revistas musicais dedicadas aos ritmos da juventude como Rincon Juvenil e Ritmo, respectivamente de 1964 e 1965. Estes periódicos, de grande circulação, veiculavam informações que conectavam os jovens chilenos às tendências da música pop internacional e ao comportamento da juventude das metrópoles mundiais.

AS DISPUTAS ENTRE O TRADICIONAL E O MODERNO NA MÚSICA FOLCLÓRICA

O surgimento de uma cultura jovem no final dos anos 50 e inicio dos 60 acirrou a tensão entre o tradicional e o moderno, expressando-se num conflito geracional. A proposição de um "novo homem" era protagonizada pelos jovens, categoria até então inexistente. Uma nova forma de estar no mundo (e relacionar-se com ele) relativizaria o peso da tradição.

Como bem afirma Montesinos (2007, p. 8), em La juventud domesticada,

[...] Somente com a crise econômica das nações ocidentais após a Segunda Guerra nos anos 50, e com o desenvolvimento de um modelo de consumo e a cultura pop nos 60 , a juventude começa a aparecer como categoria dissociada e ativa [...].

Antes disso é inconcebível falar, por exemplo, de uma moda jovem. Até esse momento os jovens eram simplesmente adultos, como seus pais. A cultura jovem aparecia como uma expressão a mais da individualidade, do desejo de liberdade manifestada em oposição às convenções sociais

Tânia da Costa Garcia. Tradição e Modernidade: reconfigurações identitárias... 
(Hobsbawm, 1995). A cultura jovem encontra-se, dessa maneira, atrelada à cultura de consumo como forma de construção de sua identidade e difusão de seus valores, a despeito de todos os discursos de oposição à sociedade capitalista, derivados deste movimento controvertido que foi a contracultura.

Neste cenário, numa tendência praticamente oposta às outras duas revistas citadas, surgia El Musiquero. No seu segundo número, em maio de 1964, o editorial explicitava a que vinha esta nova publicação. El Musiquero sairia em defesa explícita da musica folclórica nacional com a intenção de educar e convencer o ouvinte, sobretudo a juventude, da importância e superioridade deste repertório. Fica claro, também, que o alvo principal de seus ataques seria o gosto juvenil pelos ritmos importados, isto é, o rock. Assim, em suas páginas, o espaço concedido à música folclórica seria muito superior àquele reservado ao gênero nas revistas concorrentes.

Neste periódico, podem-se acompanhar as disputas entre o tradicional e o moderno, iniciadas com as boas vindas dadas ao Neofolclore por aqueles que torciam pela longevidade de um repertório nacional, mesmo que renovado.

[...] Apesar de ainda hoje dominarem alguns conjuntos estrangeiros, na maioria dos rankings, resulta ser uma grata surpresa ver, acima destes conjuntos, artistas chilenos como Los Cuatro Cuartos ou Los de las Condes disputar popularidade com o rock e o twist, com suas autênticas tonadas chilenas. A qualidade destes intérpretes, somada ao feito certo de que um grande número de bons e novos conjuntos que se perfilam, nos faz crer que, por fim, os chilenos e especialmente a juventude, esta entendendo que o primeiro deve ser o nacional, quando realmente reúne qualidade e bom gosto e este é o caso que estamos vivendo (EL Musiquero, 1965, s/p).

Um ano depois, assiste-se à detração destes mesmos grupos:

[...] O problema surge quando aparece Los Cuatro Cuartos, de cuja aparição derivou o termo neo-folclore. $\mathrm{O}$ termo foi inventado por alguém, com que fim? Com que fim não importa, mas sim a ignorância de quem $\mathrm{o}$ inventou. $\mathrm{O}$ folclore não tem dois nomes, nem sobrenome. [...] [mas enfim] o novo termo foi cunhado. [...] E hoje se fala em neo-folclore com todo desembaraço, referindo-se a uma música interpretada por uma voz alta e harmonizações discutíveis, muito discutíveis, com um mínimo de parentesco com o folclore. E aqui estamos. Com vozes ligeiramente femininas, mas nascidas de varões. É isto que chamam de neo- 
folclore... Um retorno às cantoras? Se me perguntam se o neo-folclore tem futuro eu respondo que não (El MusiQuero, 1966, p. 40-42).

Esteticamente os grupos característicos de Neofolclore inovaram nos arranjos de vozes. Mais sofisticados que os seus antecessores, os grupos possuíam um tenor, dois harmônico, e um baixo (barítono ou baixo-tenor). Também mudaram os trajes. A maioria deles, formados por jovens, vestia-se de smokey, descartando a roupa de huasos dos conjuntos de música típica. Tomavam, assim, certa distância da cultura rural, não se assumindo como portadores desta tradição, tal como seus antecessores, os interpretes da música típica. Alterou-se, ainda, a temática das canções. Extrapolando as letras que descreviam as paisagens chilenas e os temas românticos, incorporou-se a poesia de Patricio Mans e Rolando Alarcon, anunciando a presença de novos atores sociais, homens do povo, e novas paisagens, como os desertos do norte.

Dentre os grupos de Neofolclore que inauguraram a cena, estiveram Los Cuatro Cuartos, Los de Las Condes e Las Cuatro Brujas. O sucesso desses conjuntos deveu-se também ao produtor musical Camilo Fernandes e seu selo Demon, responsável pela edição dos discos da nova geração de músicos dos 60. Entretanto, vale lembrar que o termo Neofolclore foi, inicialmente, utilizado para designar todo tipo de releitura da típica musica folclórica, inclusive aquele repertório que, em seguida, representaria a Nueva Cancion Chilena.

No ano de 1964, era inaugurada a Peña de Los Parra. A iniciativa partia dos filhos de Violeta Parra, ao lado de Alarcon e Patricio Manns, agregando, em seguida, Victor Jara. A idéia era propiciar um espaço alternativo capaz de reunir jovens músicos chilenos e um público interessado num repertório que muitas vezes não se tinha oportunidade de ouvir nas rádios. A nova música folclórica incluía instrumentos andinos e propunha temáticas cada vez mais politizadas. Seus intérpretes eram geralmente homens, que se apresentavam sozinhos ou em grupos, trajados com o típico poncho andino. A Peña era freqüentada por artistas e intelectuais de esquerda chilenos e estrangeiros, unindo arte e política. Frente a tais novidades manifestaram-se, em El Musiquero, os defensores da autêntica música folclórica, avessos ao vínculo estabelecido entre canção popular e engajamento político:

[...] Tem o Chile um folclore próprio, autêntico, vigoroso e de força? Eram os precursores (Los Cuatro Huasos) formas débeis e sem força

Tânia da Costa Garcia. Tradição e Modernidade: reconfigurações identitárias... 
representativa do folclore chileno? São Los Quincheros expressões antigas, mesmo que renovada? [...] É mais valiosa uma canção de Atahualpa Yupanqui (comunista e hoje prospero comerciante) à de Eduardo Falú [...] ? é mais importante cantar um contrabandista de gado do que uma moça de tranças longas? [...] Algumas correntes políticas atuais estimam que a arte é um meio. [...] a arte não é um meio de politizar, a arte é uma forma de sentir e nada mais.[...].

Da nossa parte uma homenagem sincera a Bianchi, Clara Solovera, Flores Del Campo, Jaime Atria, Barros, Molinare e a tantos outros [...] que para fazer música chilena não olharam seus problemas políticos, nem seus fracassos, mas que criaram páginas cantadas que afortunadamente deram um prestígio ao Chile, que dificilmente poderão oferecer outros valores (El Musiquero, 1966, p. 03).

Essas palavras eram dirigidas à Patricio Manns e suas recentes declarações num programa de TV. Manns, além de compositor, era escritor e colaborava com artigos para El Musiquero. Em dezembro de 1969, este periódico publicava um texto seu polemizando, justamente, a respeito dos critérios que, em cada época e circunstância, definia o que deveria representar ou não a autêntica música folclórica chilena. A despeito da extensão do excerto, o leitor terminará concordando que sua reprodução é insubstituível:

Aqueles que pensam que as discussões sobre folclore se iniciaram em tempos recentes, por efeito do choque entre o tradicional e o moderno, com as modernas formas de vida e o desenvolvimento de novos meios de acesso a cultura, e a industrialização dos fatores que possibilitam a orientação do gosto popular, estão equivocados. Remexendo em velhos escritos, revisando jornais, coleções e revistas [...] percebe-se que há tempos [...] ninguém está de acordo. Tornado possível que o mesmo fato suscite reações tão diferentes.

Comecemos por localizar o leitor, através de uma autorizada opinião no tema central destas notas: a zamacueca. Disse Luis Alberto Sanches, escritor, historiador, investigador e jornalistas peruano, descrevendo uma Lima colonial: Entre as manifestações coreográficas daquela mistura (índio, negros e espanhóis), aparece a zamacueca. Dela derivam distintos bailes como, por exemplo, a marinera peruana, a zamba argentina e cueca chilena. A denominação cueca, derivada de zamacueca, foi abolida quando do conflito militar de 1879 [Guerra do Pacifico]. Passada a guerra, [...] se batizou como marinera a antiga zamacueca ou cueca. Tratava-se de apagar todo rastro de influência ou parentesco entre Peru e Chile, $[\ldots]$. 
Há muito mais coisas saborosas sobre isso. [...] A "Sociedade Filarmônica” criada em 1826 e integrada, entre outros, por Don José Zapiola, compositor nacional e autor do Hino de Yungay e de uma zamacueca famosa nos salões de então, "El negrito", proibiu toda dança de caráter popular caindo também sob a censura a zamacueca. Paradoxalmente o tema de Zapiola é, hoje em dia, um verdadeiro clássico do gênero. [...]

A Igreja, poucos anos mais tarde, mete-se na polêmica, através do bispo Manuel Vicuña, quem proscreveu a cueca qualificando como "coisa do pecado". Nos tempos atuais existem missas folclóricas e padres folcloristas (El Musiquero, 1969, s/p.).

Para Manns, a discussão sobre o que é folclore não estaria pautada estritamente pelas disputas entre o tradicional e o moderno. Na opinião do autor, esta seria uma polêmica mais antiga. Desdobrando seu raciocínio, ele cita diferentes exemplos, situados em distintas épocas. Conta a história da zamacuecaritmo do qual derivou a cueca chilena, a zamba argentina e a marinera peruana. De acordo com Manns, depois da Guerra do Pacifico, o gênero, no Peru, foi denominado marinera no intuito de apagar qualquer parentesco com a cueca chilena. Na seqüência, expõe dois exemplos datados de censura sobre determinadas canções do repertório popular que, posteriormente, não só foram assimiladas como se tornaram representações clássicas da musica nacional.

Se, de fato, em outras épocas, a eleição dos gêneros válidos ou não como representação do nacional foi atravessada por operações ideológicas, não há como negar que a tensão entre tradicional e o moderno foi algo característico dos anos 1950 e 1960. Nestas duas décadas, as mudanças aceleradas, que atingiram toda a sociedade, provocaram, de um lado, atitudes e comportamentos inovadores - manifestados em novas representações sociais, políticas e culturais - e, de outro, ações reativas, que em defesa do status quo proferiram um discurso de viés nacionalista.

Sobre o Festival da Nova Canção, ${ }^{3}$ organizado, em 1969, pelo radialista Ricardo Garcia, reunindo músicos afinados com esta nova tendência, novamente se pronunciaram os recalcitrantes:

Acaba de terminar na capital um festival denominado "nueva” canción chilena [...] Estiveram presentes como participantes, doze autores, todos selecionados por Ricardo Garcia e que, por seus critérios, representavam o momento atual da canção chilena.

Transcorridos os dias, pela primeira vez, queremos nos referir a este evento para manifestar que estamos totalmente de acordo com a idéia de dignificar e amparar o folclore, mas não concordamos, contudo, com a maneira como foi conduzido.

Tânia da Costa Garcia. Tradição e Modernidade: reconfigurações identitárias... 
[...] acreditamos que não é possível falar de uma "nova" canção chilena, quando se trata de folclore. O folclore rançoso, é antigo, é nobre, vem desde as fundações não se pode fazer de novo. Está feito e é assim. Podese falar de novos temas com as velhas formas, mas jamais de uma nova canção chilena, porque parece que já temos nossas formulas e que são tradicionais, belas e verídicas.

O propósito é laudatório, mas a forma não foi das mais convenientes. Oxalá em outras oportunidades a Universidade entenda que a canção chilena não tem doutrina e nem pode buscar novidades. Já está feita e como está, está bem (EL Musiquero, 1969, s/p.).

A crítica é dirigida a Ricardo Garcia, reconhecido defensor da música popular chilena, e à maneira como conduziu o Festival. Discute-se a validade do termo Nueva Cancion Chilena, do mesmo modo que se questionou no passado a denominação Neofolclore. Como este último, a Nueva Cancion seria mais uma vez um desvirtuamento, uma ameaça à autêntica música folclórica. Afirma-se, ainda, que a "canção chilena não tem doutrina e nem pode buscar novidades" referindo-se provavelmente ao engajamento político do movimento.

A Nueva Cancion Chilena, justamente pelo seu engajamento político, não só desagradou os guardiões da tradição como também não chegou a se popularizar com a mesma intensidade que Neofolclore ou o rock chileno nos meios e comunicação. No entanto, isso não impediu que Arriba la Cordillera, de Patricio Manns, alcançasse absoluto sucesso de venda ${ }^{4}$ ou que as canções de Rolando Alarcon se tornassem populares e, ainda, que Victor Jara tivesse canções premiadas no Festival de Viña del Mar.

A origem do movimento e seus desdobramentos estiveram, indubitavelmente, ligados ao fenômeno de massificação da música popular chilena e da cultura jovem. Se sua difusão foi mais restrita, todavia, não deixou de acontecer. As grandes gravadoras, como a RCA-Victor e a Philips, investiram neste segmento, ao mesmo tempo em que era criada, no ano de1968, pela juventude comunista, a Discoteca del Canto Popular (DICAP), garantindo espaço para os trabalhos dos músicos mais militantes, comprometidos com a candidatura de Allende pela Unidade Popular.

\section{Considerações finals}

A definição de um determinado repertório musical capaz de representar a identidade do povo chileno tornou-se, durante as décadas de 1950 e 1960, uma tarefa não só abraçada por acadêmicos e políticos, mas tam- 
bém por críticos e produtores musicais, radialistas e artistas daquele país. Embora toda a acusação de deturpação do folclore fosse dirigida aos interesses espúrios do mercado, aos disk jockeys e aos sem compromisso com a cultura nacional, a importância dos meios de comunicação para a preservação e a divulgação do cancioneiro popular foi fundamental. Se, por um lado, tais veículos não propagaram o autêntico imaginado pelos puristas acadêmicos, por outro, inventaram sua própria tradição. Com o surgimento das novas tendências - o neofolclore, o rock e a nova canção -, os detratores das novas gerações elegeram a denominada "música típica chilena", leia-se, o folclore massivo, como representação da "verdadeira" música popular nacional.

A reprovação cairia, todavia, mais sobre a nueva cancion do que sobre o neofolclore, devido ao viés mais explicitamente político desta última. Não há duvidas de que essas tendências juvenis, que se polarizariam politicamente no final dos anos 1960, foram fenômenos que nasceram atrelados ao mercado e necessitaram de seus suportes tecnológicos para atingirem seus fins.

Portanto, os desdobramentos destas disputas em torno da autêntica música popular chilena demonstram que, por trás da discussão, estava, de fato, em pauta as controvérsias relacionadas à superação definitiva, após a Segunda Grande Guerra, de uma sociedade tradicional por outra moderna, expressa, essa última, nas tecnologias de comunicação que passavam a moldar as representações do nacional em função das novas demandas sociais, anunciando as mudanças políticas que atingiram o país.

Tradition and Modernity: Identity Rearrangements in the Chilean Folk Music of THE 50's AND 60's.

AвSTRACT: The urban popular song is a cultural event typically modern. Their production, spreading and consumption are confused with the urbanization process and the availability of technological resources. Communicated by the mass media, when achieved broader public than the local receivers, it has transformed into an important vector of cultural homogenization, what happened considerably fast, within the logic of the market. This article aims to map the connections between the popular song, the formation and consolidation of a consumer market and the political uses of it in different sectors of Chilean society between the fifties and sixties, a period in which the arts were related to the struggles of representation around the national identity in different countries of Latin America.

KEY-WORDS: Folk music, national identity and youth culture.

Tânia da Costa Garcia. Tradição e Modernidade: reconfigurações identitárias... 
NOTAS

1 Vale lembrar que a relação entre identidade nacional e cultura popular tem início com os estudos folclóricos surgidos na Europa do século XIX, em decorrência da necessidade de constituição de uma identidade para a nação. Em busca da "essência do povo", os folcloristas nomearam o mundo campesino como depositário de um passado comum capaz de representar o espírito nacional, em detrimento do universo urbano degradado, corrompido, visto como ameaça a esta unidade. O que interessava era o "passado em vias de extinção". A despeito das polêmicas internas entre os folcloristas foi, basicamente, esta concepção de folclore que alcançou o século XX, norteando os debates em torno dos critérios para se definir a cultura nacional.

2 Na América Latina dos anos 1950 não se pode falar de uma sociedade de consumo estabelecida, consolidada, mas de bolsões de consumo. É notável a existência de áreas mais desenvolvidas, como as metrópoles, cuja presença expressiva das camadas médias garantia o desenvolvimento do mercado.

3 Desde então, as canções com tais características - temática política ou somente folclórica, cantadas por vozes masculinas em grupo ou em solo e arranjos com instrumentos andinos, além dos tradicionais da música popular chilena passaram a ser denominadas Nueva Cancion Chilena.

4 O LP chegou a ser inclusive lançado no Brasil pela Copacabana com o título $E l$ Sueño Americano. Consta no disco somente o ano de edição no Chile, 1967.

\section{FONTES}

ECRAN n. $1220.08 / 06 / 1954$, p.18

EL MUSIQUERO, n. 13, abril de 1965.

EL MUSIQUERO, n. 27, fevereiro de 1966.

EL MUSIQUERO, n.32, agosto de 1966.

EL MUSIQUERO, n.92, junho de 1969.

EL MUSIQUERO, n.78, dezembro de 1969.

\section{REFERÊNCIAS}

Canclini, N. Culturas híbridas. São Paulo: Edusp, 1998.

Hobsbawm, Eric; Ranger, Terence. A invenção das tradições. Rio de Janeiro: Paz e Terra, 1997.

Martin-Barbero. Dos meios as mediações. Rio de Janeiro: Ed. da UFRJ, 1997.

História Revista, Goiânia, v. 13, n. 2, p. 483-495, jul./dez. 2008 
Montesinos, D. La juventud domesticada. Madrid: Editorial Popular, 2007.

SMith, Anthony, Comemorando a los muertos, inspirando a los vivos. Mapas recuerdos y moralejas em la recreación de las identidades nacionales. Revista Mexicana de Sociologia, v. 60, n. 1, p. 61-80, 1998.

VilHENA, Luís Rodolfo. Projeto e missão: o movimento folclórico brasileiro, 19471964. Rio de Janeiro: Ed. da FGV, 1997.

Tânia da Costa Garcia. Tradição e Modernidade: reconfigurações identitárias... 